\title{
ОСОБЕННОСТИ БЮДЖЕТНО-ПРАВОВОГО ЗАКРЕПЛЕНИЯ СТИМУЛОВ И ОГРАНИЧЕНИЙ В УСЛОВИЯХ КРИЗИСНОЙ СИТУАЦИИ В ГОСУДАРСТВЕ
}

\author{
Л. Л. Бобкова \\ Воронежский государственный университет \\ Поступила в редакцию 2 ноября 2020 г.
}

\begin{abstract}
Аннотация: анализируется механизм бюджетно-правового регулирования обновленного законодательства в условиях эконолической и политической нестабильности в государстве. Исследуются средства правового регулирования, которыли выступают бюджетно-правовые норлы-стилульь и бюджетно-правовые норль-ограничения. Вводятся новые понятия, и раскрывается их сущность в области бюджетного законодательства. Практическая значилость введения новых правовых конструкиий для бюджетного права обусловлена существующими измененияли бюджетного законодательства в условиях панделии.
\end{abstract}

Ключевые слова: норльь, механизл бюджетно-правового регулирования, структура бюджетно-правовой нормы, стилуль и ограничения, бюджетно-правовые норлы-стилулы и бюджетно-правовые норлы ограничения.

\begin{abstract}
: this article analyzes the mechanism of budgetary and legal regulation in the context of updated legislation in the context of economic and political instability in the state. The means of legal regulation are investigated, which are budgetary legal norms-incentives and budgetary legal norms-restrictions. In the context of the subject under study, the author introduces new concepts, and reveals their essence in the light of existing changes in budgetary legislation. The practical significance of the introduction of new legal structures for budget law is due to the existing changes in budget legislation in the context of a pandemic.
\end{abstract}

Key words: norms, mechanism of budgetary legal regulation, structure of budgetary legal norms, incentives and restrictions, budgetary legal norms incentives and budgetary legal norms restrictions.

198 Социальная и экономическая ситуация в Российском государстве, сформировала целый комплекс защитных мер в механизме реализации публичного управления, которые закрепляются в бюджетно-правовых нормах в виде стимулов и ограничений.

Стимулы и ограничения закрепляются в бюджетно-правовых нормах, которые являются теми правовыми инструментами, посредством которых осуществляется бюджетно-правовое регулирование и в целом публичное управление.

(C) Бобкова Л. Л., 2021 
В отечественной теории права правовое регулирование определяется как процесс целенаправленного воздействия на общественные отношения со стороны государства при помощи правовых норм¹ .

Следуя общепринятым научным подходам, любая норма права имеет свою структуру: гипотезу, диспозицию и санкцию ${ }^{2}$ Основываясь на этом, можно утверждать, что бюджетно-правовые нормы, которые содержат стимулы и ограничения имеют также аналогичную структуру.

Представляется, что стимулы и ограничения в бюджетном праве можно рассматривать в широком и узком смысле. Если мы говорим о широком смысле, то стимулы и ограничения - это бюджетно-правовые нормы, которые являются правовыми инструментами в механизме бюджетно-правового регулирования, посредством чего реализуется публичное управление в области финансов.

Исходя из данного подхода, бюджетно-правовые нормы-стимулы имеют гипотезу, диспозицию и положительную санкцию ${ }^{3}$. Напротив, бюджетно-правовые нормы-ограничения среди указанных элементов, включают в себя отрицательную санкцию, предусматривающую негативные последствия для нарушителя.

Если мы говорим об узком подходе к пониманию стимулов и ограничений в бюджетном праве, то полагаем, что это отдельный элемент бюджетно-правовой нормы, а именно санкция (положительная или отрицательная).

В теории права вопросам стимулирования и ограничения посвящено значительное число научных работ.

В частности, А. В. Малько в своих работах отмечает многообразие правовых стимулов. С его точки зрения, «в зависимости от того, в каком элементе нормы права содержатся, правовые стимулы можно выделить юридический фракт-стимул (гипотеза), субъективное право, законный интерес, льгота и т. п. (диспозиция), поощрение (санкция)» ${ }^{4}$.

Однако для бюджетного права характерны стимулы и ограничения, которые имеют свое закрепление в других частях бюджетно-правовой нормы.

Следуя той финансовой политике, которая осуществляется в Российской Федерации в связи с предотвращением финансового кризиса и сохранением экономической стабильности, можно выделить следующие

${ }^{1}$ См.: Поляков A. В., Тилошина E. В. Общая теория права : учебник. СПб., 2015. C. 269-270.

${ }^{2}$ См.: Малько А. В. Стимулы и ограничения в праве. Теоретико-информационный аспект / под ред. Н. И. Матузова. Саратов, 1994. С. 44.

${ }^{3}$ Развивая научную концепцию о положительных санкциях, мы также поддерживаем идею, что не всегда последние являются мерами принудительного воздействия к правонарушителю. Концепция о положительных санкциях эволюционирует в бюджетном праве. Так, бюджетно-правовая норма, содержащая стимул, имеет положительную санкцию (см.: Поляков А. B., Тимошина E. B. Указ. соч. С. 340-341).

${ }^{4}$ Малько А. В. Указ. соч. С. 44. 
виды стимулирования и ограничений, которые закреплены сегодня в нормах бюджетного права:

1. Бюджетно-правовые стимулы в виде фринансовой поддержки субъектов РФ и муниципальных образований в организации мероприятий по борьбе с COVID-19, а именно:

а) стимулом для субъекта РФ является самостоятельная возможность внесения изменений в бюджетную роспись бюджета субъекта РФ без внесения изменений в закон о бюджете субъекта РФ в случае перераспределения бюджетных ассигнований на фринансовое обеспечение мероприятий по борьбе с COVID-19. Иными словами, субъект РФ, исходя из эпидемиологической ситуации в своем регионе, может самостоятельно финансировать строительство больниц, закупать необходимое количество медицинского инвентаря для борьбы с пандемией с учетом специфики своего региона.

Так, в соответствии с фредеральным законом Правительство РФ и высшие органы исполнительной власти субъектов РФ имеют право перераспределять соответственно между субъектом РФ, муниципальным образованием бюджетные ассигнования, предусмотренные в федеральном бюджете, бюджете субъекта РФ, для предоставления субвенций, субсидий и иных межбюджетных трансфертов; в данном случае у субъекта РФ расширены полномочия с учетом эпидемиологической обстановки соответствующего региона, самостоятельно перераспределять бюджетные ассигнования между муниципальными образованиями для предоставления межбюджетных трансрертов ${ }^{5}$;

б) стимулом для субъекта РФ является перенос Правительством РФ периода погашения реструктурированных обязательств (задолженности) перед Российской Федерацией ${ }^{6}$;

в) стимулом для субъектов РФ является самостоятельная возможность использования бюджетных ассигнований, выделенных из федерального

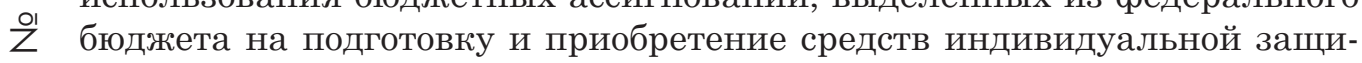
ты, бюджетные ассигнования из федерального бюджета, выделенные на развертывание коечной сети для лечения больных ${ }^{7}$, иначе говоря, бюд-

5 О внесении изменений в отдельные законодательные акты Российской

200 Федерации в целях принятия неотложных мер, направленных на обеспечение устойчивого развития экономики и предотвращение последствий распространения новой коронавирусной инфекции : федер. закон от 8 июня 2020 г. № 166-ФЗ. URL: www.kremlin.@.ru

${ }^{6}$ Поручения Президента РФ Правительству РФ от 1 апреля 2020 г. URL: www. kremlin.@.ru ; O внесении изменений в Федеральный закон «О приостановлении отдельных положений Бюджетного кодекса Российской Федерации и установление особенностей исполнения федерального бюджета в 2020 году : федер. закон от 1 апреля 2020 г. № 103-Ф3. URL: www.kremlin.@.ru

${ }^{7}$ Поручение Президента РФ Правительству РФ от 8 апреля 2020 г. URL: www. kremlin@ru ; O внесении изменений в Федеральный закон «О приостановлении отдельных положений Бюджетного кодекса Российской Федерации и установление особенностей исполнения фредерального бюджета в 2020 году» : федер. закон от 1 апреля 2020 г. № 103-Ф3. URL: www.kremlin.@.ru 
жетные ассигнования из федерального бюджета являются стимулом для субъекта РФ, так как создают фонансовую стабильность по использованию бюджетных ассигнований не из своего бюджета, а из федерального бюджета для предотвращения пандемии

д) стимулом для субъекта РФ является предоставление бюджетных кредитов, а также возможности увеличения установленного бюджетным законодательством субъекта РФ максимального размера бюджетного кредита на пополнение остатков средств на счетах бюджетов субъекта РФ и местных бюджетов

е) стимулом для субъекта РФ является увеличение срока предоставления бюджетного кредита из бюджета субъекта РФ бюджету другого субъекта РФ до 3 лет ${ }^{10}$.

2. Бюджетно-правовые стимулы, направленные на создание фринансового благополучия и социальной поддержки семей, имеющих детей в возрасте до 16 лет, в организации мероприятий по борьбе с COVID-19, a именно бюджетные ассигнования ${ }^{11}$ :

а) на единовременные пособия семьям, имеющих детей до 3 лет;

б) пособия по уходу за ребенком до 3 лет увеличены в 2 раза;

в) единовременные пособия детям в возрасте от 3 до 16 лет.

В данном случае речь идет о бюджетно-правовых нормах-стимулах, которые направлены на фринансовую поддержку семей в условиях пандемии.

3. Бюджетно-правовые стимулы, направленные на создание фринансового благополучия и социальной поддержки граждан, признанных в установленном порядке безработными и имеющих несовершеннолетних детей, в организации мероприятий по борьбе с COVID-19, а именно бюджетные ассигнования:

- на выплату в период с 1 апреля по 30 июня 2020 г. гражданам, признанным в установленном порядке безработными после 1 марта 2020 г.;

- пособия по безработице в повышенном размере (независимо от условий признания гражданина безработным);

- выплату гражданам, признанным безработными и имеющим несовершеннолетних детей, 3 тысячи рублей в месяц на каждого ребенка.

${ }^{8} \mathrm{O}$ внесении изменений в Федеральный закон «О приостановлении действия отдельных положений Бюджетного кодекса Российской Федерации и установлении особенностей исполнения фредерального бюджета в 2020 году» : фредер. закон от 1 апреля 2020 г. № 103-Ф3. URL: www.kremlin.@.ru

${ }^{9}$ См. подробнее: Статья 93, прим. 3 Бюджетного кодекса РФ. Доступ из информ.-правовой системы «Гарант».

$10 \mathrm{O}$ внесении изменений в отдельные законодательные акты Российской Федерации в целях принятия неотложных мер, направленных на обеспечение устойчивого развития экономики и предотвращение последствий распространения новой коронавирусной инфекции : федер. закон от 8 июня 2020 г. № 166-ФЗ. URL:www.kremlin.@.ru

${ }^{11} \mathrm{O}$ дополнительных мерах социальной поддержки семей, имеющих детей : указ Президента РФ от 7 апреля 2020 г. № 249. URL: www.kremlin.@.ru 
4. Бюджетно-правовые стимулы, направленные на финансовую поддержку работников здравоохранения, непосредственно оказывающих помощь больным с COVID-1912.

5. Бюджетно-правовые стимулы, направленные на финансовую поддержку особо пострадавших от ограничительных мер в условиях пандемии, а именно:

a) снижение размера социальных взносов для малого и среднего бизнеса с 30 до $15 \%$.

Данная мера стимулирующего характера носит долгосрочный характер, имеет долгосрочную цель - создание дополнительных ресурсов у предприятия для оплаты труда работников;

б) рассрочка уплаты налогов отдельным категориям налогоплательщиков, подразумевающая реструктуризацию задолженности на 6 и более месяцев, а также ее погашение ежемесячными платежами равными долями в течение года ${ }^{13}$.

Рассмотрим на указанных выше примерах структуру бюджетно-правовых норм-стимулов. Данная структура традиционно включает в себя следующие элементы:

- гипотеза, а именно сформулированное в норме условие, при котором стимулируемый субъект может получить некие преимущества по отношению к другим субъектам;

- диспозиция, как известно, это правило поведения, определяющее права и обязанности субъектов. В бюджетно-правовой норме-стимуле диспозиция устанавливает обязанность компетентных органов предоставить субсидию при достижении положительного результата, предусмотренную гипотезой, и право получателя субсидии претендовать на ее получение;

- положительная санкция ${ }^{14}$.

Рассмотрим выделенную структуру на примере бюджетно-правовых норм-стимулов, предусматривающих финансовую поддержку субъектов малого бизнеса, пострадавших от пандемии. В данной норме под гипотезой мы понимаем соответствие основного ОКВЭД предпринимателя одному из видов деятельности, наиболее пострадавших от пандемии ${ }^{15}$.

${ }^{12} \mathrm{O}$ предоставлении дополнительных страховых гарантий отдельным категориям медицинских работников : указ Президента РФ от 6 мая 2020 г. № 313. URL: www.kremlin.@.ru

${ }^{13} \mathrm{O}$ внесении изменений в Бюджетный кодекс Российской Федерации и Федеральный закон «О приостановлении действия отдельных положений Бюджетного кодекса Российской Федерации и установлении особенностей исполнения бюджетов бюджетной системы Российской Федерации в 2020 году» : фредер. закон от 25 мая 2020 г. URL: kremlin.ru ; О внесении изменений в часть вторую Налогового кодекса Российской Федерации : федер. закон от 8 июня 2020 г. № 172-Ф3. URL: www.kremlin.@.ru

${ }^{14}$ Напомним, что вопрос о положительных санкциях поднимается в работах А. В. Полякова (см.: Поляков А. В., Тилошина Е. В. Указ. соч. С. 340-341).

$15 \mathrm{O}$ внесении изменений в отдельные законодательные акты Российской Федерации в целях принятия неотложных мер, направленных на обеспечение 
Диспозицией данной нормы является правило поведения, которому должно следовать лицо, претендующее на стимулирование, а именно: отсутствие предпринимательской деятельности в период пандемии, сохранение не менее 80 \% в штате работников малого предприятия.

Санкцией данной нормы будет предоставление субсидии.

Что же касается бюджетно-правовых норм, которые содержат ограничения, то, как справедливо замечено, «правовые стимулы должны разумно сочетаться с правовыми ограничениями, ведь для законодателя важно не только побуждать к социально полезному поведению, но и сдерживать поведение социально вредное, которое может причинить урон интересам личности, коллектива, государства и общества» ${ }^{16}$.

Рассмотрим подробнее элементы бюджетно-правовой нормы-ограничения. Гипотезой бюджетно-правовой нормы-ограничения является реализащия бюджетно-правовой нормы-стимула.

Диспозицией бюджетно-правовых норм-ограничений является нарушение правила поведения, устанавливающего субъекту обязанность по соблюдению условий предоставления бюджетно-правовых стимулов.

Санкция бюджетно-правовых норм-ограничений определяет негативные последствия для субъекта, нарушившего диспозицию. При этом санкция такой бюджетно-правовой нормы может содержаться как в самом документе, так и иметь отсылочный характер к другим законам.

Проиллюстрируем данный подход на следующем примере. Так, гипотезой бюджетно-правовой нормы-ограничения является получение бюджетно-правовых мер поддержки субъектами малого бизнеса (например, субсидия $)^{17}$.

Диспозицией бюджетно-правовой нормы-ограничения является нарушение условий предоставления субсидий (например, продолжение предпринимательской деятельности, несмотря на запрет ее осуществления, сокращение штата работников предприятия и т. п.).

Санкцией бюджетно-правовой нормы-ограничения является принудительный возврат предоставленной субсидии.

Установленная Бюджетным кодексом РФ необходимость возврата субсидий в соответствующий бюджет в случае нарушения условий, установленных при их предоставлении, направлена, прежде всего, на стимулирование добросовестного исполнения получателями субсидий условий предоставления средств из бюджета бюджетной системы Российской

устойчивого развития экономики и предотвращение последствий распространения новой коронавирусной инфекции : федер. закон от 8 июня 2020 г. № 166-ФЗ. URL: www.kremlin.@.ru

${ }^{16}$ Малько А. В. Указ. соч. С. 6.

${ }_{17}$ Об утверждении Правил предоставления в 2020 году из федерального бюджета субсидий субъектам малого и среднего предпринимательства, ведущим деятельность в отраслях российской экономики, в наибольшей степени пострадавших в условиях ухудшения ситуации в результате распространения новой коронавирусной инфекции : постановление Правительства РФ от 24 апреля 2020 г. № 576. URL: www.kremlin.@.ru 
Федерации, а также на обеспечение восстановления средств бюджета в размере, эквивалентном выявленному нарушению.

Данная мера обеспечивает восстановление прав и соблюдение законных интересов публично-правового образования, предоставившего бюджетные средства получателю субсидии на определенных нормативными правовыми актами и (или) соглашениями (договорами) условиях.

Обязанность по восстановлению права публично-правового образования, нарушенного в результате действия (бездействия) получателя субсидии, ответственностью не является, поскольку ответственность представляет собой обязанность виновного лица отвечать за противоправные действия (бездействие), т. е. за совершенные правонарушения ${ }^{18}$.

Как видим, это санкция, которая предусматривает меру государственного принуждения, для субъекта, нарушившего предписания бюджетно-правовой нормы-стимула. Санкция бюджетно-правовых норм-ограничений имеет место и тогда, когда субъект, в компетенцию которого входит право поощрять, нарушает данную норму ${ }^{19}$.

Суммируя изложенное выше, можно утверждать, что в условиях пандемии и связанных с ней ограничений в экономике законодатель был вынужден вносить коррективы в бюджетное законодательство в области применения стимулов и ограничений.

Данные изменения и практика их применения проиллюстрировали значимость стимулов и ограничений как средств правового регулирования и предопределили необходимость развития финансово-правовой доктрины в направлении их более глубокого изучения.

${ }^{18} \mathrm{O}$ возврате субсидий в соответствующий бюджет в случае нарушения условий, установленных при их предоставлении : письмо Минфина России от 28 апреля 2016 г. № 02-10-06/24775. Доступ из справ.-правовой системы «КонсультантПлюс».

${ }^{19}$ См.: Баранов В. М. Поощрительные нормы советского социалистического права / под ред. М. И. Байтина. Саратов, 1978. С. 48-57.

204 верситет

Воронежский государственный уни-

Бобкова Л. Л., кандидат юридических наук, доцент кафбедры фбинансового права

E-mail: bobkovalily@yandex.ru
Voronezh State University

Bobkova L. L., Candidate of Legal Sciences, Associate Professor of the Financial Law Department

E-mail: bobkovalily@yandex.ru 